\title{
Sodium Glucose Cotransporter-2 Inhibitors in Clinical Practice: Impact beyond Glycemic Control
}

\author{
${ }^{1}$ Karthik Rao N, ${ }^{2} \mathrm{KM}$ Prasanna Kumar
}

\section{ABSTRACT}

Type 2 diabetes mellitus is a metabolic disorder that occurs due to an interplay of multiple perplexing pathophysiological mechanisms and leads to hyperglycemia. However, till date there has been no single unique molecule that can by itself effectively address all the metabolic abnormalities occurring in type 2 diabetes. Furthermore, type 2 diabetes must be managed with agents that can combat hyperglycemia without causing hypoglycemia and adverse cardiovascular outcomes. Thus, the need of the hour is for a unique molecule that can deliver beyond glycemic control and can in addition address the cardiovascular risk factors that arise in type 2 diabetes. Sodium glucose cotransporter-2 (SGLT-2) inhibitors are the latest of the oral hypoglycemic agents that act by insulin-independent mechanisms and tackle several cardiovascular risk factors that occur in type 2 diabetes. The scope of this article will be to focus primarily on the cardiovascular benefits of SGLT-2 inhibitors and its actions beyond glycemic control in providing a comprehensive care in the management of type 2 diabetes.

Keywords: Cardiovascular safety, Extra antihyperglycemic actions, Review, Sodium glucose cotransporter-2 inhibitors, Type 2 diabetes.

How to cite this article: Rao NK, Kumar KMP. Sodium Glucose Cotransporter-2 Inhibitors in Clinical Practice: Impact beyond Glycemic Control. Hypertens J 2016;2(2):74-79.

\section{Source of support: Nil}

Conflict of interest: None

\section{INTRODUCTION}

Sodium glucose transporter-2 (SGLT-2) inhibitors are the latest of the oral hypoglycemic agents introduced in the management of type 2 diabetes. Unlike most of the oral hypoglycemic agents, this novel group of agents seems to be promising and encouraging due to its insulin-independent action causing negligible and imperceptible risk of hypoglycemia. Besides its antihyperglycemic action, the SGLT-2 inhibitors have been consistently proven to promote weight loss, reduce

\footnotetext{
${ }^{1}$ Assistant Professor, ${ }^{2}$ Consultant

${ }^{1}$ Department of Medicine, Kasturba Medical College, Manipal Karnataka, India

${ }^{2}$ Department of Endocrinology, CDEC and Bangalore Diabetes Hospital, Bengaluru, Karnataka, India

Corresponding Author: Karthik Rao N, Assistant Professor Department of Medicine, Kasturba Medical College, Manipal Karnataka, India, Phone: +919886124423, e-mail: karthikrao85@ gmail.com
}

blood pressure, and act complementary to the current treatment modalities.

\section{Sodium Glucose Cotransporter-2 Receptors in Type 2 Diabetes}

It is well known that uncontrolled type 2 diabetes leads to glycosuria owing to the saturation of the SGLT- 2 receptors involved in glucose reabsorption. Nevertheless, despite the severe hyperglycemia, SGLT-2 receptors surprisingly continue to reabsorb glucose through an insulinindependent mechanism. ${ }^{1}$ Curiously, despite the high blood glucose levels, uncontrolled diabetes causes the upregulation of SGLT-2 leading to augmented renal tubular glucose reabsorption (Fig. 1). Thus, the threshold for glucose saturation is altered with diabetes and increased glucose reabsorption occurs owing to the overexpression of the SGLT-2 molecules. ${ }^{2}$ Thus, SGLT- 2 inhibitors cause glucose lowering effect in an insulin-independent mechanism by arresting the increased reabsorption of glucose across the renal tubules (Figs 2 and 3). The drugs that are currently available for use in India include canagliflozin, dapagliflozin, and empagliflozin.

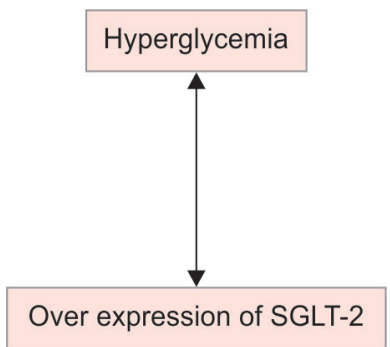

Fig. 1: Complementary role of hyperglycemia and SGLT-2 inhibitors. (Hyperglycemia induces the overexpression of SGLT-2 receptors which by enhanced glucose reabsorption leads to exacerbation of the prevailing hyperglycemia.)

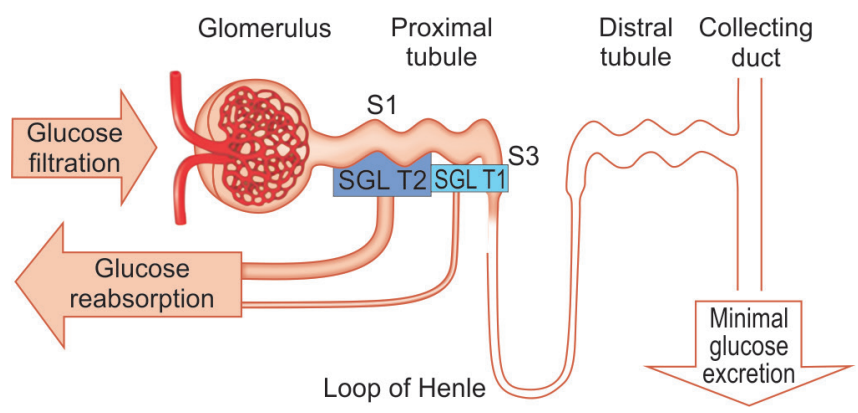

Fig. 2: Normal location and function of SGLT-2 receptor 


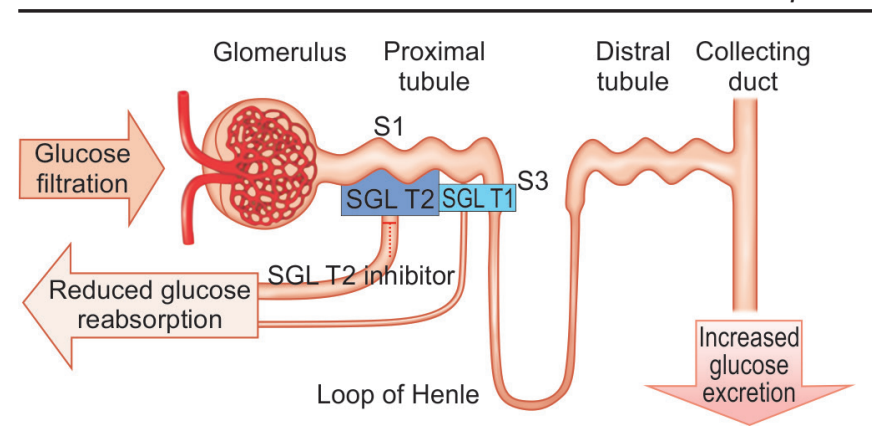

Fig. 3: Mechanism of action of SGLT-2 inhibitors

\section{The Unique Mode of Action of SGLT-2 Inhibitors}

Till date, the oral hypoglycemic agents used in type 2 diabetes have focused primarily on insulin-dependent mechanisms to counteract hyperglycemia, such as increasing the secretion of endogenous insulin. However, the efficacy of the agents acting through insulin signaling and dependant pathways will be compromised over time due to the deterioration of beta cell function that ensues with the progression of diabetes. ${ }^{3}$ Thus there is a need for a drug that will address the multiple challenges involved in achieving sustained glycemic control by insulin-independent mechanisms.

Familial renal glycosuria, a condition without any sinister clinical consequences occurs due to the genetic mutation in the SGLT-2 receptor that can lead to significant glycosuria (up to $134 \mathrm{~g}$ /day reported) but has normal renal tubular structure and function. Thus, learning from familial glycosuria, SGLT-2 inhibitors appear to be safe molecules and by their unique insulin-independent mode of action are promising in combating hyperglycemia in a dependable and sustained manner.

\section{THE NEED FOR SGLT-2 INHIBITORS: AN INDIAN PERSPECTIVE}

The phenotype of Indians with type 2 diabetes varies significantly from their western counterparts in being more insulin-resistant due to increased abdominal obesity, having unfavorable lipid profiles with increase in atherogenic small dense LDL cholesterol, increase in C-reactive protein (CRP) levels, and low adiponectin, making them susceptible to cardiovascular events ${ }^{4,5}$ ("The thin fat Indian"). To make matters worse, the onset of diabetes is a decade earlier among Indians and generally associated with a poor and inadequate beta cell reserve due to a delay in diagnosis. ${ }^{6,7}$ The prevailing therapies in the management of type 2 diabetes have several limitations and flaws like weight gain, risk of hypoglycemia, gastrointestinal side effects, and the inability to maintain effective and persistent longterm glycemic control. However, with the advent of this novel class of SGLT-2 inhibitors, the shortcomings in the current pharmacological therapies will be addressed effectively.

\section{SODIUM GLUCOSE COTRANSPORTER-2 INHIBITORS: BENEFITS BEYOND GLYCEMIC CONTROL}

Apart from its antihyperglycemic effect, SGLT-2 inhibitors have been consistently shown to induce weight loss, reduce blood pressure, and act complementary to the prevailing treatment modalities. ${ }^{8-10}$ In addition, SGLT-2 inhibitors can potentially target the numerous risk factors for atherosclerosis in type 2 diabetes, such as visceral adiposity, hyperinsulinemia, arterial stiffness, albuminuria, uric acid, and oxidative stress. The reduction in body weight with SGLT-2 inhibitors was attributed to the loss of about 200 to 300 calories per day through glucose excretion in urine. In an intriguing study, the addition of dapagliflozin in patients uncontrolled on metformin monotherapy resulted in increased oxidation of fatty acids compared to placebo, supporting the mechanism of fat breakdown and catabolism as a fundamental cause of weight loss. The reduction in body weight achieved was largely due to the reduction in the total body fat mass in the visceral and subcutaneous adipose tissue. This hypothesis was supported with the use of dual-energy X-ray absorptiometry (DEXA), which revealed a significantly greater reduction in adipose stores among patients receiving dapagliflozin in comparison with patients who received placebo. ${ }^{11}$

In a study conducted with the use of canagliflozin at doses of 100 and $300 \mathrm{mg}$ resulted in a significant decrease in the blood pressure and a reduction in the body weight. In the overall population, least-square (LS) mean percent reductions in body weight with canagliflozin 100 and $300 \mathrm{mg}$ were -2.9 and $-3.6 \%$ respectively. In the Indian subgroup of patients, mean percent decrease in body weight with canagliflozin 100 and $300 \mathrm{mg}$ were -2.5 and $-3.2 \%$ respectively. The LS mean reduction in systolic blood pressure (SBP) with canagliflozin 100 and $300 \mathrm{mg}$ were -3.4 and $-4.1 \mathrm{~mm} \mathrm{Hg}$ respectively. In the Indian subgroup, canagliflozin 100 and $300 \mathrm{mg}$ were associated with -3.4 and $-4.4 \mathrm{~mm} \mathrm{Hg}$ decrease in the BP. In the overall population, canagliflozin 100 and $300 \mathrm{mg}$ were associated with a diastolic BP reduction of -1.9 and $-1.9 \mathrm{~mm} \mathrm{Hg}$ respectively, and a reduction of -0.5 and $-0.7 \mathrm{~mm} \mathrm{Hg}$ in the diastolic BP in the Indian subgroup. The study demonstrated that despite the relatively lower baseline body weight and BMI of the patients in the Indian subgroup in comparison to the overall population, canagliflozin was associated with convincing reductions in the body weight. ${ }^{12}$ Comparable outcomes of weight loss ranging from -2.7 to $-3.2 \mathrm{~kg}$ at 24 weeks of therapy were obtained 
with $10 \mathrm{mg}$ dapagliflozin. ${ }^{13}$ In patients with inadequate glycemic control with potentially weight-gaining oral hypoglycemic agents, addition of dapagliflozin resulted in a significantly greater loss of weight in comparison to glimepiride (dapagliflozin, $-2.26 \mathrm{~kg}$ vs placebo, $-0.72 \mathrm{~kg}$ ) and also blunted the increase in weight associated with the use of pioglitazone up to week 48 (dapagliflozin, $+0.69 \mathrm{~kg}$ vs placebo, $+2.99 \mathrm{~kg}$ ). ${ }^{14,15}$ Dapagliflozin when introduced as an add-on to insulin therapy maintained weight near baseline, and escalating doses of insulin resulted in a steady weight gain in the placebo group (dapagliflozin, $-1.5 \mathrm{~kg}$ vs placebo, $+0.9 \mathrm{~kg}$ ). ${ }^{16}$

Owing to SGLT-2 inhibitor's insulin-independent mechanism for glycemic control, reductions in body weight and $\mathrm{BP}$ will be the ideal pharmacological agent to initiate treatment in the Asian population who typically are severely insulin-resistant and having a poor beta-cell reserve. ${ }^{17}$ The weight loss achieved with SGLT-2 inhibitors would enhance the insulin sensitivity and arrest the progression of beta cell failure that ensues over time with diabetes. ${ }^{18}$ This revival in the beta-cell function and enhanced insulin sensitivity has been shown to last even on sustained therapy with SGLT-2 inhibitors. ${ }^{19}$

\section{PROPOSED NON-GLYCEMIC ACTIONS OF SGLT-2 INHIBITORS IN CURTAILING CARDIOVASCULAR RISK FACTORS}

Apart from hyperglycemia, the pathogenesis of cardiovascular complications in diabetes is multifactorial and thus mandates a comprehensive approach in the management. Hence, it would be phenomenal if an oral hypoglycemic agent could provide benefits over and above glycemic control alone. Among the oral hypoglycemic agents currently available, SGLT-2 inhibitors appear to be the prime molecule that can provide additional cardiovascular benefits. The proposed mechanisms of extra glycemic effects and cardiovascular risk factor modulation with SGLT-2 inhibitors are elaborated below.

\section{Reduced Risk of Hypoglycemia}

The sympathetic nervous system stimulation that occurs in response to hypoglycemia causes a decline in the glomerular filtration rate (GFR) by blunting the action of SGLT-2 inhibitors..$^{20}$ In addition, the ability to counteract postprandial glycemic excursions and reduced glycemic variability and enhanced insulin sensitivity with SGLT-2 inhibitors could perhaps translate into favorable cardiovascular outcomes. ${ }^{21}$

\section{Reduction in BP and Arterial Stiffness}

Sodium glucose cotransporter-2 inhibitors have consistently shown to decrease BP even without a compensatory increase in the heart rate. The antihypertensive action is multifactorial and involves diuretic-like action, loss of sodium, decrease in weight, and reduction in the arterial tone. ${ }^{22}$

\section{Improvement in Endothelial Function or the Vascular Architecture}

Sodium glucose cotransporter-2 inhibitors alter the structural proteins present in the connective tissue of the vessel wall like collagen, elastin, and abnormal glycation of proteins, which occur due to hyperglycemia and improve endothelial dysfunction. ${ }^{23}$

\section{Reduction in Visceral Adiposity}

This action is unique to SGLT-2 inhibitors in comparison to other oral hypoglycemic agents and may translate in reducing the cardiovascular outcomes. ${ }^{24}$

\section{Effects on Proteinuria and Kidney Function}

Sodium glucose cotransporter-2 inhibitors reduce urinary albumin excretion and the intra-glomerular hypertension by altering the tubuloglomerular feedback due to increased distal sodium delivery. ${ }^{25}$

\section{Reduction in Levels of Uric Acid}

In addition, the glycosuria that ensues with the use of SGLT-2 inhibitors will alter the transport activity of uric acid in the renal tubules and reduce the serum uric acid levels that are generally elevated in metabolic syndrome. ${ }^{26}$

\section{Effect on Lipid Parameters}

Sodium glucose cotransporter-2 inhibitors increase the levels of both high-density lipoprotein-cholesterol (HDL-C) and low-density lipoprotein-cholesterol (LDL-C) with no change in HDL-C/LDL-C ratio. This increase in LDL-C levels may negate some of the potential benefits of SGLT-2 inhibitors. ${ }^{27}$

\section{Effects on Other Cardiovascular Risk Pathways}

Animal studies have shown that SGLT-2 inhibitors reduce oxidative stress and leukocytosis induced by hyperglycemia that are fundamental in the pathogenesis of atherosclerosis. ${ }^{28}$ With reductions in the blood pressure, weight, and diuresis, SGLT-2 inhibitors can potentially benefit treatment of patients with cardiac failure. Studies done in rats with heart failure have shown decrease in left ventricular mass and left ventricular end diastolic diameter with SGLT-2 inhibitors. ${ }^{29}$

\section{The HbA1C Paradox}

Most of the oral hypoglycemic agents as well as insulin cause reduction in $\mathrm{HbA1C}$ at the cost of weight gain 
i.e., associated with adverse outcomes. Patients who gained weight during treatment for type 2 diabetes had 1.8- to 2.3-fold increase in risk of cardiovascular disease compared with those who gained less weight or who lost weight. ${ }^{30}$ Every $3 \mathrm{~kg}$ gain in weight offsets the benefits of $\mathrm{HbA1C}$ reduction by $1 \% .{ }^{31} \mathrm{In}$ an article published in LANCET endocrinology, an increase in weight by $1 \mathrm{~kg}$ due to treatment with antidiabetic medications leads to a relative increase in risk of heart failure. ${ }^{32}$ Thus, conventional antihyperglycemic agents, despite causing satisfactory reduction in $\mathrm{HbA1C}$, will cause collateral damage due to weight gain. Hence, minimizing risk of weight gain is of utmost priority that can be effectively achieved with the novel class of SGLT-2 inhibitors.

The "EMPA-REG" study is a landmark study that demonstrated cardiovascular safety of SGLT-2 inhibitor empagliflozin. ${ }^{33}$ Notably, the benefits observed with empagliflozin were seen in high-risk cardiovascular type 2 diabetes patients on treatment with statins, aspirin, and drugs blocking the renin-angiotensin-aldosterone axis. The study involved 7,020 patients randomized to receive once daily empagliflozin 10 or $25 \mathrm{mg}$ against placebo. The primary endpoint was death from cardiovascular causes, non-fatal myocardial infarction, or non-fatal stroke among the pooled empagliflozin group vs the placebo group. The major secondary composite outcome was the primary outcome and hospitalization for unstable angina. The primary outcome occurred in 490 of 4,687 patients (10.5\%) in the pooled empagliflozin group and in 282 of 2,333 patients $(12.1 \%)$ in the placebo group (hazard ratio in the empagliflozin group, 0.86 ; $95.02 \%$ confidence interval, 0.74 to $0.99 ; \mathrm{p}=0.04$ for superiority). Remarkably, the decrease in the risks of death from cardiovascular causes and from any cause occurred early in the trial persisted all through the study. There were no significant betweengroup differences in the rates of myocardial infarction or stroke, but in the empagliflozin group there were significantly lower rates of death from cardiovascular causes $(3.7 \%$ vs $5.9 \%$ in the placebo group; $38 \%$ relative risk reduction), hospitalization for heart failure (2.7 and $4.1 \%$ respectively; $35 \%$ relative risk reduction) and death from any cause (5.7 and $8.3 \%$ respectively; $32 \%$ relative risk reduction). There was no significant between-group difference in the key secondary outcome $(p=0.08$ for superiority). For the first time, the EMA-REG study has demonstrated that an antihyperglycemic agent to be not just non-inferior but rather superior over placebo in high-risk type $2 \mathrm{DM}$ patients. Does this translate to other SGLT2 inhibitors or not? Is this a molecular effect of empagliflozin or class effect of SGLT-2 inhibitors that can only be substantiated with ongoing studies like Canagliflozin Cardiovascular Assessment Study (CANVAS)?

\section{SIDE EFFECTS OF SGLT-2 INHIBITORS}

The enhanced glycosuria that ensues with the use of SGLT-2 inhibitors leads to an increased risk of urinary tract infections, pyelonephritis, and candidiasis. ${ }^{34-36}$ In addition, SGLT-2 inhibitors cause osmotic diuresis and polyuria that can lead to volume depletion and electrolyte abnormalities. This risk is markedly enhanced with combination of SGLT-2 inhibitors with diuretics. Accordingly, SGLT-2 inhibitors must be avoided in individuals presenting with the classical hyperglycemic symptoms of polyuria, polydipsia, polyphagia, and unintentional weight loss. The actions of SGLT-2 inhibitors are blunted with renal impairment obligating dose modifications and are not advocated for use with moderate-to-severe renal disease.

Of late, the US FDA has issued a warning on the risk of developing euglycemic ketoacidosis with SGLT-2 inhibitors. This is a matter of concern as the diagnosis may be unseen and missed due to lack of awareness among the treating clinicians and the absence of severe hyperglycemia that is typically associated with diabetic ketoacidosis. It is hypothesized that the euglycemic ketoacidosis is due to the hyperglucagonemia, non-insulin-dependent glucose clearance, and volume depletion that occur with SGLT-2 inhibitors. ${ }^{37}$ Hence, euglycemic ketoacidosis must be strongly suspected in patients on SGLT-2 inhibitors developing nausea, vomiting, or metabolic acidosis. Thus, SGLT-2 inhibitors are not approved for treatment in individuals with type 1 diabetes and must be used with utmost caution in individuals having an increased risk of developing diabetic ketoacidosis. In April 2016, the European Medicines Agency (EMA) has initiated a review on canagliflozin in the ongoing Canagliflozin Cardiovascular Assessment Study after an increase in risk in amputations, mostly of the great toe was observed. The Canagliflozin Cardiovascular Assessment Study is a randomized study of about 4,000 type 2 diabetes patients with high cardiovascular risks to canagliflozin 100 or $300 \mathrm{mg}$ daily or to placebo and will be completed by 2017. The EMA Pharmacovigilance Risk Assessment Committee (PRAC) has appealed to the pharmaceutical company to assess for the increased risk in toe amputations with canagliflozin.

\section{CURRENT POSITIONING OF SGLT-2 INHIBITORS IN THE MANAGEMENT OF DIABETES}

Metformin unless contraindicated is the first and the best drug to commence pharmacological therapy in type 2 diabetes. ${ }^{38}$ However, the dilemma has been on the molecule to complement metformin therapy. Sulfonylureas, DPP-IV inhibitors, and pioglitazone 
have always been the preferred choice of second-line antidiabetic therapy till lately. Nevertheless, these drugs are associated with adverse effects like weight gain, hypoglycemia, edema, increased risk of fractures, and cardiovascular safety concerns. Certainly, SGLT-2 inhibitors with its unique mode of action and safety profile are an ideal add-on therapy to metformin. Various international and national guidelines, such as the Research Society for the Study of Diabetes in India (RSSDI) guidelines and algorithm for management of type 2 diabetes have accepted SGLT-2 inhibitors as the add-on therapy after metformin. ${ }^{39}$ In a study published by Davidson et $\mathrm{al}_{,}^{40}$ canagliflozin produced comparable outcomes among different ethnic populations. The study demonstrated identical reductions in HbA1c, body weight, and SBP among the Hispanic/Latino and non-Hispanic/Latino patients with type 2 diabetes. In a subset analysis of canagliflozin global studies that was performed on Indian type 2 diabetic patients has been promising and has shown that SGLT-2 inhibitors are equally effective and safe in the Indian type 2 diabetic population. ${ }^{41}$ Our experience with SGLT-2 inhibitors in the last 1 year has been encouraging and satisfactory as monotherapy and as add-on to other oral and injectable antidiabetic agents.

\section{CONCLUSION AND FUTURE THOUGHTS}

With its unique mode of action, safety profile, and innumerable benefits beyond glycemic control, the SGLT2 inhibitors appear to be "the blockbuster molecule" that will assist the physician in achieving optimal and sustained glycemic control. The EMPA-REG study has demonstrated that SGLT-2 inhibitors are cardiacfriendly oral hypoglycemic agents. Does this mean that cardiologists should prescribe SGLT-2 inhibitors among all cases of diabetes having high cardiovascular risk and especially among those with cardiac failure? Will SGLT-2 inhibitors be equally effective in patients of diabetes with low cardiovascular risk in preventing all-cause mortality, cardiovascular mortality, and morbidity? Only time will answer these unanswered questions.

\section{REFERENCES}

1. Tahrani AA, Barnett AH. Dapagliflozin: a sodium glucose cotransporter 2 inhibitor in development for type 2 diabetes. Diabetes Ther 2010 Dec;1(2):45-56.

2. Nair S, Wilding J. Sodium glucose cotransporter 2 inhibitors as a new treatment for diabetes mellitus. J Clin Endocrinol Metab 2010 Jan;95(1):34-42.

3. Campbell RK, Cobble ME, Reid TS. Distinguishing among incretin-based therapies. Pathophysiology of type 2 diabetes mellitus: potential role of incretin-based therapies. J Fam Pract 2010 Sep;59(9 Suppl 1):S5-S9.
4. Mohan V, Sandeep S, Deepa R, Shah B, Varghese C. Epidemiology of type 2 diabetes: Indian scenario. Indian J Med Res 2007 Mar;125(3):217-230.

5. Ramachandran A, Snehalatha C, Viswanathan V. Burden of type 2 diabetes and its complications - the Indian scenario. Curr Sci 2002;83:1471-1476.

6. Sosale A, Prasanna Kumar KM, Sadikot SM, Nigam A, BajajS, Zargar AH, Singh SK. Chronic complications in newly diagnosed patients with type 2 diabetes mellitus in India. Indian J Endocrinol Metab 2014 May-Jun;18(3):355-360.

7. Unnikrishnan R, Anjana RM, Mohan V. Diabetes in South Asians: is the phenotype different? Diabetes 2014 Jan;63(1): 53-55.

8. Leiter LA, Yoon KH, Arias P, Langslet G, Xie J, Balis DA, Millington D, Vercruysse F, Canovatchel W, Meininger G. Canagliflozin provides durable glycemic improvements and body weight reduction over 104 weeks vs glimepiride in patients with type 2 diabetes on metformin: a randomized, double-blind, phase 3 study. Diabetes Care 2015 Mar;38(3):355-364.

9. Bode B, Stenlöf K, Harris S, Sullivan D, Fung A, Usiskin K, Meininger G. Long-term efficacy and safety of canagliflozin over 104 weeks in patients aged 55 to 80 years with type 2 diabetes. Diabetes Obes Metab 2015 Mar;17(3):294-303.

10. Neumiller JJ, White JR Jr, Campbell RK. Sodium-glucose co-transport inhibitors: progress and therapeutic potential in type 2 diabetes mellitus. Drugs 2010 Mar 5;70(4):377-385.

11. Bolinder J, Ljunggren O, Kullberg J, Johansson L, Wilding J, Langkilde AM, Sugg J, Parikh S. Effects of dapagliflozin on body weight, total fat mass and regional adipose tissue distribution in patients with type 2 diabetes mellitus with inadequate glycemic control on metformin. J Clin Endocrinol Metab 2012 Mar;97(3):1020-1031.

12. Kumar KM, Mohan V, Sethi B, Gandhi P, Bantwal G, Xie J, Meininger G, Qiu R. Efficacy and safety of canagliflozin in patients with type 2 diabetes mellitus from India. Diabetes Res Clin Prac 2014 Nov;106:S260-S261.

13. Ferrannini E, Ramos SJ, Salsali A, Tang W, List JF. Dapagliflozin monotherapy in type 2 diabetic patients with inadequate glycemic control by diet and exercise: a randomized, doubleblind, placebo-controlled, phase III trial. Diabetes Care 2010 Oct;33(10):2217-2224.

14. Strojek K, Yoon KH, Hruba B, Elze M, Langkilde AM. Effect of dapagliflozin in patients with type 2 diabetes who have inadequate glycaemic control with glimepiride: a randomized, 24-week, double-blind, placebo-controlled trial. Diabetes Obes Metab 2011 Oct;13(10):928-938.

15. Rosenstock J, Vico M, Wei L, Salsali A, List J. Dapagliflozin added-on to pioglitazone reduces $\mathrm{HbA1c}$ and mitigates weight gain with low incidence of hypoglycemia in type 2 diabetes [abstract]. Diabetes 2011;60:A270:986-P.

16. Wilding JP, Woo V, Soler NG, Pahor A, Sugg J, Rohwedder K, Parikh S, Dapagliflozin 006 Study Group. Long-term efficacy of dapagliflozin in patients with type 2 diabetes mellitus receiving high doses of insulin: a randomized trial. Ann Intern Med 2012 Mar 20;156(6):405-415.

17. Ma RC, Chan JC. Type 2 diabetes in East Asians: similarities and differences with populations in Europe and the United States. Ann N Y Acad Sci 2013 Apr;1281(1):64-91.

18. Bays H, Blonde L, Rosenson R. Adiposopathy: how do diet, exercise and weight loss drug therapies improve metabolic disease in overweight patients? Expert Rev Cardiovasc Ther 2006 Nov;4(6):871-895. 
19. Polidori D, Mari A, Ferrannini E. Canagliflozin, a sodium glucose co-transporter 2 inhibitor, improves model-based indices of beta-cell function in patients with type 2 diabetes. Diabetologia 2014 May;57(5):891-901.

20. Patrick AW, Hepburn DA, Swainson CP, Frier BM. Changes in renal function during acute insulin-induced hypoglycaemia in patients with type 1 diabetes. Diabet Med 1992 Mar;9(2):150-155.

21. Heise T, Seman L, Macha S, Jones P, Marquart A, Pinnetti S, Woerle HJ, Dugi K. Safety, tolerability, pharmacokinetics, and pharmacodynamics of multiple rising doses of empagliflozin in patients with type 2 diabetes mellitus. Diabetes Ther 2013 Dec;4(2):331-345.

22. Lambers Heerspink HJ, de Zeeuw D, Wie L, Leslie B, List J. Dapagliflozin a glucose-regulating drug with diuretic properties in subjects with type 2 diabetes. Diabetes Obes Metab 2013 Sep;15(9):853-862.

23. Zimlichman R. Treatment of hypertension and metabolic syndrome: lowering blood pressure is not enough for organ protection, new approach-arterial destiffening. Curr Hypertens Rep 2014 Oct;16(10):479.

24. Neeland IJ, McGuire DK, Chilton R, Crowe S, Lund SS, Woerle HJ, Broedl UC, Johansen OE. The sodium glucose co-transporter 2 inhibitor (SGLT2i) empagliflozin reduces weight and markers of visceral adiposity (VA) in type 2 diabetes (T2D) in short- and intermediate term. Diabetes and Vascular Disease Research. 2016 Mar;13(2):119-126.

25. Cherney D, Lund SS, Perkins BA, Groop PH, Cooper ME, Kaspers S, Pfarr E, Woerle HJ, von Eynatten M. The effect of sodium glucose cotransporter 2 inhibition with empagliflozin on microalbuminuria and macroalbuminuria in patients with type 2 diabetes. Diabetologia. 2016 Jun 17.

26. Chino Y, Samukawa Y, Sakai S, Nakai Y, Yamaguchi J, Nakanishi T, Tamai I. SGLT-2 inhibitor lowers serum uric acid through alteration of uric acid transport activity in renal tubule by increased glycosuria. Biopharm Drug Dispos 2014 Oct;35(7):391-404.

27. Hardy E, Ptanszynska A, de Bruin TWA, Johnsson E, Parikh SJ, List JF. Changes in lipid profiles of patients with type 2 diabetes mellitus on dapagliflozin therapy. Diabetologia 2013;(Suppl 947):61.

28. Tahara A, Kurosaki E, Yokono M, Yamajuku D, Kihara R, Hayashizaki Y, Takasu T, Imamura M, Li Q, Tomiyama H, et al. Effects of SGLT2 selective inhibitor ipragliflozin on hyperglycemia, hyperlipidemia, hepatic steatosis, oxidative stress, inflammation, and obesity in type 2 diabetic mice. Eur J Pharmacol 2013 Sep;715(1-3):246-255.

29. Younis FM, Hollander K, Mayoux EW, Landa-Rouben N, Nachman R, Leor Y. Effect of prophylactic treatment with empagliflozin on cardiac function and diabetes in $\mathrm{CRDH}$ rats. Diabetes.2014;63(Suppl 1) A273 (1056-P).

30. Eeg-Olofsson K,CederholmJ,NilssonPM,Zethelius B,NunezL, Gudbjörnsdóttir S, Eliasson B. Risk of cardiovascular disease and mortality in overweight and obese patients with type 2 diabetes: an observational study in 13,087 patients. Diabetologia 2009 Jan 1;52(1):65-73.

31. McEwan P, Evans M, Kan H, Bergenheim K. Understanding the inter-relationship between improved glycaemic control, hypoglycaemia and weight change within a long-term economic model. Diabetes Obes Metab 2010 May 1;12(5): 431-436.

32. Udell JA, Cavender MA, Bhatt DL, Chatterjee S, Farkouh ME, Scirica BM. Glucose-lowering drugs or strategies and cardiovascular outcomes in patients with or at risk for type 2 diabetes: a meta-analysis of randomised controlled trials. Lancet Diabetes Endocrinol 2015 May 31;3(5):356-366.

33. Zinman B, Wanner C, Lachin JM, Fitchett D, Bluhmki E, HantelS, Mattheus M, Devins T, Johansen OE, Woerle HJ, et al. Empagliflozin, cardiovascular outcomes, and mortality in type 2 diabetes. N Eng J Med 2015 Nov 26;373(22):2117-2128.

34. Johnsson KM, Ptaszynska A, Schmitz B, Sugg J, Parikh SJ, List JF. Vulvovaginitis and balanitis in patients with diabetes treated with dapagliflozin. J Diabetes Complications 2013 Sep-Oct;27(5):479-484.

35. InzucchiSE, Bergenstal RM, Buse JB, Diamant M, Ferrannini E, Nauck M, Peters AL, Tsapas A, Wender R, Matthews DR, et al. Management of hyperglycemia in type 2 diabetes, 2015: a patient-centered approach: update to a position statement of the American Diabetes Association and the European Association for the Study of Diabetes. Diabetes Care 2015 Jan;38(1):140-149.

36. Nyirjesy P, Sobel JD, Fung A, Mayer C, Capuano G, Ways K, Usiskin K. Genital mycotic infections with canagliflozin, a sodium glucose co-transporter 2 inhibitor, in patients with type 2 diabetes mellitus: a pooled analysis of clinical studies. Curr Med Res Opin 2014 Jun;30(6):1109-1119.

37. Rosenstock J, Ferrannini E. Euglycemic diabetic ketoacidosis: a predictable, detectable, and preventable safety concern with SGLT2 inhibitors. Diabetes Care 2015 Sep;38(9):1638-1642.

38. Garber AJ, Abrahamson MJ, Barzilay J, Blonde L, Bloomgarden ZT, Bush MA, Dagogo-Jack S, Davidson MB, Einhorn D, Garber JR, et al. AACE/ACE comprehensive diabetes management algorithm 2015. Endocr Pract 2015 Apr;21(4):438-447.

39. Madhu SV, Saboo B, Makkar BM, Reddy GC, Jana J, Panda JK, Singh J, Setty N, Rao PV, Chawla R, et al. RSSDI clinical practice recommendations for management of type 2 diabetes mellitus, 2015. Int J Diabetes Dev Ctries 2015 Oct;35(Suppl 1):S1-S71.

40. Davidson AJ, Auilar R, Lavalle González FJ, Trujillo A, Alba M, Vijapurkar U, Meininger G. Efficacy and safety of canagliflozin in patients with type 2 diabetes mellitus of different ethnicity. Ethn Dis 2016 Apr 21;26(2):221-228.

41. Kumar KP, Mohan V, Sethi B, Gandhi P, Bantwal G, Xie J, Meininger G, Qiu R. Efficacy and safety of canagliflozin in patients with type 2 diabetes mellitus from India. Indian journal of endocrinology and metabolism. 2016 May;20(3):372. 